\title{
Induction of $\mathbf{R}$ Bodies by Ultraviolet Light in Killer Paramecia
}

\author{
By LOUISE B. PREER, BERTINA M. RUDMAN AND J. R. PREER JUN. \\ Department of Zoology, Indiana University, Bloomington, Indiana \\ AND A. JURAND \\ Instititute of Animal Genetics, Edinburgh, Scotland
}

(Received 22 June 1973; revised I3 August 1973)

\begin{abstract}
SUMMAR Y
Kappa, a bacterial endosymbiont present in killer stocks of Paramecium aurelia, exists in two forms - brights, which contain a refractile (R) body, and non-brights which lack the $\mathrm{R}$ body. Non-brights are self-reproducing and give rise to brights, which cannot reproduce and are toxic to sensitive paramecia which ingest them. Associated with the $\mathrm{R}$ body are structures resembling bacteriophages in form and chemical composition. Animals of stock 5I, syngen 4 of $P$. aurelia were given low doses of ultraviolet light. The percentage of brights increased markedly, beginning $6 \mathrm{~h}$ after irradiation. In three experiments, absolute numbers of kappas were determined $\mathrm{I} 3$ to $\mathrm{I} 4 \mathrm{~h}$ after exposure to u.v.: the number of brights increased and nonbrights decreased significantly, while the total number of kappas remained the same. At $24 \mathrm{~h}$, after irradiation the numbers of kappa particles had decreased considerably; after 3 days they were completely gone. The results are consistent with the hypothesis that the phage-like structures exist as u.v.-inducible prophages in non-brights, and that when a non-bright becomes a bright, the prophage is spontaneously induced forming, at the same time, mature phage-like elements and the $\mathrm{R}$ body. These events constitute the lytic cycle which ends with the destruction of the bright.
\end{abstract}

\section{INTRODUCTION}

For several years there has been a growing suspicion that kappa, the bacterial endosymbiont responsible for the killer trait in Paramecium, is infected with an element similar to a temperate bacteriophage. The present study supports this view by demonstrating effects on kappa that can be explained by assuming that the phage is inducible with ultraviolet light.

Kappa was first detected genetically as a cytoplasmic factor responsible for the killer phenotype (Sonneborn, 1943) and later demonstrated cytologically (Preer, I950). Killer stocks of paramecia liberate kappa into the fluid in which they grow. Kappa may then be taken up from the medium by sensitive paramecia, causing distinctive pre-lethal effects and eventual death. Recent studies have supported the view that kappa and the various other endosymbionts of $P$. aurelia are bacteria. (See reviews by Preer, 197I; Preer, Preer \& Jurand, 1973.) Kappa is unique among the endosymbionts of $P$. aurelia in that it is the only one in which a small refractile inclusion called the $\mathrm{R}$ body can develop (Beale, Jurand \& Preer, 1969). Kappa-bearing paramecia have two kinds of kappa: one contains one or more $\mathrm{R}$ bodies, does not reproduce, frequently lyses, is toxic to sensitive paramecia which ingest it, and is known as a bright; the other is self-reproducing, gives rise to brights, and is called a non-bright (Preer, Siegel \& Stark, I953; Smith, I96I; Mueller, 1963). When a bright is ingested by a sensitive paramecium, the $\mathrm{R}$ body, which is a proteinaceous ribbon rolled up 
into a coil, suddenly unrolls, rupturing the food vacuole membrane (Jurand, Rudman \& Preer, 197I), and death ensues. On the innermost coil of the $\mathrm{R}$ body, phage-like structures are seen (Preer \& Preer, 1967), spherical in some stocks and helical in others (Preer, Jurand, Preer \& Rudman, 1972).

It has been shown that when an $\mathrm{R}$ body is formed, kappa loses its ability to reproduce. Preer \& Jurand (I968) and Grimes \& Preer (I97I) showed that the presence of phage-like structures is almost perfectly correlated with the presence of the $\mathrm{R}$ body in kappa of stocks 7 and 562. Using caesium chloride density-gradient centrifugation, the spherical phage-like structures of stock 562 of Paramecium aurelia were isolated and found to contain DNA and protein in approximately equal amounts (Preer, Preer, Rudman \& Jurand, 1971). These properties support the view that these structures are indeed phage-like. It has been suggested that non-bright kappa harbours a prophage. According to this hypothesis, when the nonbright gives rise to a bright, the prophage is induced and at the same time the $\mathrm{R}$ body is formed (Preer \& Preer, I967). Nothing smaller than an intact $R$ body is able to kill a sensitive paramecium, but the nature of the toxin and the extent to which the $R$ body and the phage are implicated are unknown. There is evidence that killing is not brought about by the replication of phage DNA in sensitive paramecia, but rather is related to the protein of the R body or the phage (Jurand, Rudman \& Preer, I97I).

U.v. is known to induce prophage in many lysogenic bacteria. If kappa is a lysogenic bacterium its prophage might be inducible by u.v. and, because the presence of phage is correlated with the presence of the $\mathrm{R}$ body, this should result in an increase in bright kappas. We have obtained this result which gives strong support to the hypothesis that kappa contains an inducible prophage. Although we found an increase in brights after irradiation, there was no concomitant increase in killing activity.

\section{METHODS}

Culture. Animals of stock 5I, syngen 4, Paramecium aurelia were cultured in some experiments in ordinary bacterized Cerophyll medium at 2 fissions/day for at least 2 weeks before using (see Sonneborn, 1970). In other experiments paramecia were cultured in bacteria-free medium containing Chlamydomonas reinhardi in order to count brights and non-brights in homogenates of paramecia, avoiding confusion of non-brights with bacteria which they closely resemble. The method was as follows: Chlamydomonas medium, consisting of $\mathrm{I} g$ yeast autolysate (Basamin Busch), $0.25 \mathrm{~g}$ sodium acetate, $0.625 \mathrm{~g}$ Cerophyll, $0 \cdot \mathrm{I} 25 \mathrm{~g}$ dibasic sodium phosphate, and $\mathrm{I} 1$ of double-distilled water, was put into test-tubes and autoclaved. Using sterile technique, a small inoculum of $C$. reinhardi, strain $89^{+}$(kindly supplied by Dr Richard Starr, Indiana University, U.S.A.) was placed into the tube of medium and incubated under fluorescent light at $22{ }^{\circ} \mathrm{C}$ for 2 days before using. Bacteriafree paramecia were obtained by transferring paramecia in this medium from one depression to the next in sterile depression slides over a period of several hours, according to the procedure described by Heatherington (1934). Bacteria-free paramecia obtained by this method were inoculated singly into test-tubes half-full of Chlamydomonas medium and kept in ordinary room light. During the next 3 to 4 days most of the Chlamydomonas were ingested, yielding a good population of paramecia. Cultures were fed twice a week to allow for a doubling of paramecia at each feeding, and on the day before irradiation an additional 2 to $3 \mathrm{ml}$ of medium was added for each $12 \mathrm{ml}$ of culture of paramecium.

Irradiation. The cultures were irradiated at a distance of $40 \mathrm{~cm}$ from a 15 watt germicidal Champion G I $5 \mathrm{~T} 8$ lamp providing $253 \cdot 7 \mathrm{~nm}$ u.v. light and irradiated for $\mathrm{I} \cdot 5 \mathrm{~min}$, previously 
determined as optimal for the increased production of $\mathrm{R}$ bodies. Cultures received approx. $22 \mathrm{erg} / \mathrm{s} / \mathrm{mm}^{2}$. Immediately after irradiation all cultures were placed in a stainless steel moist chamber and kept at $22{ }^{\circ} \mathrm{C}$ in the dark. Several depression slides containing Io to $\mathrm{2}$ drops of bacterized cultures of paramecia in each depression were irradiated and an equal number was kept as control. Prior to irradiation, the bacteria-free paramecia cultured in tubes of Chlamydomonas medium were removed to sterile Petri plates using sterile technique. For each test, 4 Petri plates containing $15 \mathrm{ml}$ of culture of paramecium each were used, 2 plates for control and 2 for irradiated cultures. After irradiation, control and irradiated cultures were treated alike.

Counts of bright and non-bright kappas. To compare the percentage of brights in irradiated and control bacterized paramecia, fresh squashes of whole animals were made. Slide cultures were removed from the dark at stated intervals after irradiation. Several animals were washed through 3 depressions of a depression slide containing sterile yeast autolysate ( $\mathrm{g} / \mathrm{l}$ of Basamin Busch) and were allowed to remain in the third depression for $\mathrm{I} h$. This was sufficient to remove most of the bacteria in the paramecia and avoid confusion of bacteria and non-brights when making counts. Several washed animals were crushed between slide and coverslip (Preer \& Stark, I953) and observed with bright phase microscopy. Counts were made of the number of brights observed in a total of $I 200$ to 1500 kappas (brights plus non-brights) for each control and each irradiated culture at a given time after irradiation.

To compare the absolute numbers of brights and non-brights, homogenates of paramecia cultured bacteria-free in Chlamydomonas medium were used. At a specified time after irradiation, control and irradiated cultures were each filtered through cotton in a sterile porcelain filter and centrifuged in an oil testing centrifuge to concentrate the paramecia approx. I00-fold. The exact concentration factor in each case was noted. The supernatant was removed with suction and a population count of the paramecia in the precipitate was made. After adding $0^{\cdot} \mathrm{I} \mathrm{ml}$ of a suspension of yeast $\left(\mathrm{I}^{8} \mathrm{cells} / \mathrm{ml}\right.$, standardized with a haemocytometer) to $0.3 \mathrm{ml}$ of a culture of paramecium containing between 35000 and 100000 paramecia/ml, the mixture was homogenized by ejecting it forcibly through a $2.5 \mathrm{ml}$ syringe several times. A microdrop of this homogenate was placed on a slide, fixed for Io $\mathrm{s}$ with osmic tetroxide vapour, covered with a coverslip and sealed with Vaseline. Using bright phase microscopy, the numbers of yeast cells, brights and non-brights were recorded until a total of at least Ioo yeast cells was counted in each preparation.

Killing tests. These were performed using homogenates according to methods already described (Sonneborn, I970) using stock 3I sensitives. After incubation the number of affected animals (corpses, animals with aboral humps or abnormal body shape) was recorded.

Electron microscopy. Paramecia were fixed, sectioned and stained according to methods already described (Jurand, Rudman and Preer, I97I).

\section{RESULTS}

\section{The effect of irradiation on percentage of brights}

Counts of kappas from four paramecia were made, scoring the number of brights in a total of 300 to $400 \mathrm{kappas} /$ paramecium for each control and each irradiated culture observed at a given time after irradiation. The proportion of brights in each animal and the overall proportions were computed (Fig. I). The percentage of brights among total kappas rose from about $25 \%$ to over $70 \%$ during the $24 \mathrm{~h}$ following irradiation. It was found using chi-square contingency tests that in many cases the four animals within a group differed significantly from each other. Accordingly, $95 \%$ confidence limits for each group of four 


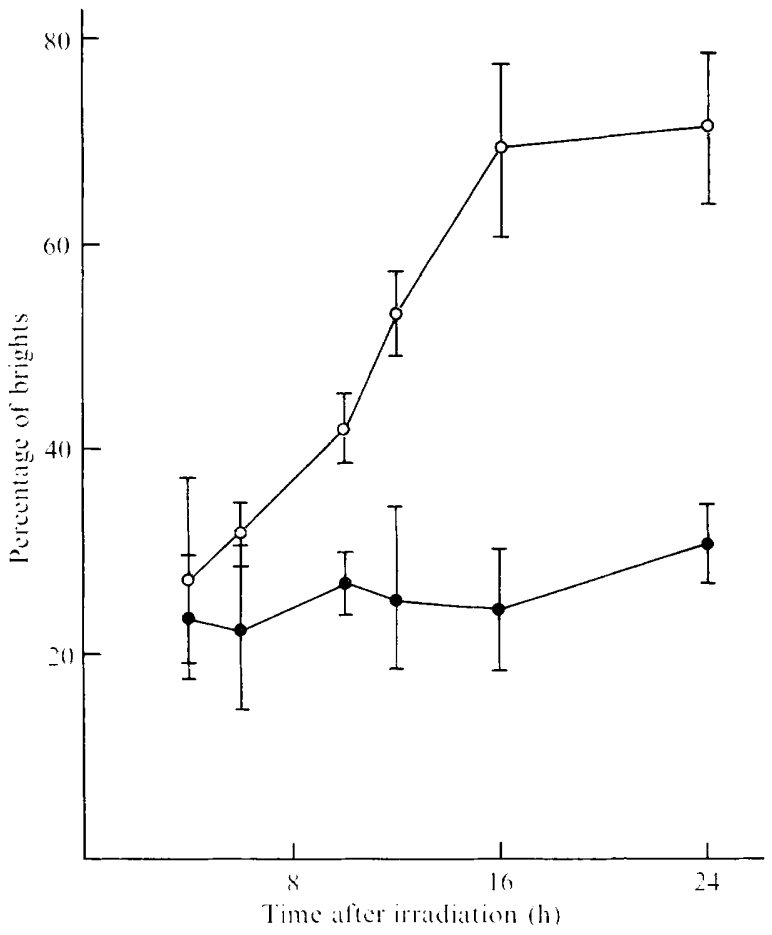

Fig. I. Percentage of bright kappas among total kappas in control ( $\odot$ ) and irradiated $(\bigcirc)$ cultures after irradiation with u.v. The dosage was $22 \mathrm{erg} / \mathrm{s} / \mathrm{mm}^{2}$ for $\mathrm{I} \cdot 5 \mathrm{~min}$. The vertical bars represent $95 \%$ confidence limits.

animals were computed using $t$ and the arc-sine transformation of the proportions. The confidence limits are given on the graph. Note that the proportion of brights began to rise sharply about 4 to $6 \mathrm{~h}$ after irradiation and then began to level off after $\mathrm{I} 6 \mathrm{~h}$.

Observations with the electron microscope of sectioned paramecia which were fixed $10.5 \mathrm{~h}$ after irradiation confirmed the induction of $\mathrm{R}$ bodies with u.v.; $62 \%(5 \mathrm{I} / 82)$ of the sections of kappa from the irradiated group were brights, as opposed to $27 \%(45 / 166)$ brights in the controls. Furthermore, in the irradiated group $37 \%$ (I9/5I) of the sections of brights had only I to 4 turns of ribbon in the coiled R body rather than the normal number of 8 to $\mathrm{I} 2$; in the control group only $4 \%(2 / 45)$ had as few as I to 4 turns. Obviously when fixation occurred the many induced $\mathrm{R}$ bodies were just beginning to develop and there were numerous short ribbons with only a few turns. Many were too small to be visible with phase microscopy, accounting for the lower percentage of brights $(42 \%)$ recorded in Fig. I at $10.5 \mathrm{~h}$ after irradiation.

\section{Effect of irradiation on the absolute numbers of brights and non-brights}

Although the previous experiments showed that the proportion of brights increases after irradiation, it does not necessarily follow that $\mathrm{R}$ body formation is induced by u.v. The effect might result from differential destruction of bright and non-bright kappas. An attempt was made to determine the total numbers of $R$ bodies in individual animals after irradiation by counting the $\mathrm{R}$ bodies in and around single crushed animals. Although the method showed considerable variability in counts, it was clear that the total number of $\mathrm{R}$ bodies, 
Table I. Mean no. of kappas/paramecium, I3 to 14 h after u.v.-irradiation

$\begin{array}{lcc}\text { Expt I } & \text { Control } & \text { Irradiated } \\ \text { Brights } & 444 & 739 \\ \text { Non-brights } & 772 & 442 \\ \text { Total kappa } & 1216 & 118 \mathrm{I} \\ \text { Expt.2 } & & \\ \text { Brights } & 333 & 622 \\ \text { Non-brights } & 612 & 176 \\ \text { Total kappa } & 945 & 798 \\ \text { Expt 3 } & & \\ \text { Brights } & 733 & 1121 \\ \text { Non-brights } & 1567 & 855 \\ \text { Total kappa } & 2300 & 1976\end{array}$

including those within brights and those free, increased markedly after irradiation. In one experiment, for example, $\mathrm{I} 9 \mathrm{~h}$ after irradiation the number of $\mathrm{R}$ bodies in three treated paramecia was 106, 122 and 121 respectively, while the number in three control paramecia was 30,68 and 35 .

Because of the rather variable results and the difficulty of making total counts of nonbrights in the squashes, an alternative method was developed which involved making counts in homogenates of control and irradiated animals. For these experiments, large numbers of animals free of bacteria were needed. The simple method used in the previous experiments of washing a few animals with a micropipette in order to reduce the bacterial population was not adequate. Therefore cultures of paramecia free of bacteria but growing on living Chlamydomonas were used. In a preliminary experiment counts were made $5,8,13$ and $24 \mathrm{~h}$ after irradiation. The greatest difference between control and irradiated cultures appeared in the I $3 \mathrm{~h}$ group, where there was a significant increase in the number of brights and decrease in non-brights although the total number of kappas had not decreased. At $24 \mathrm{~h}$ after irradiation, the total number of kappas had decreased markedly and the proportion of brights was very high in irradiated cultures; non-brights had decreased more than brights. In other experiments kappa was entirely lost 3 days after irradiation. In view of these considerations, I 3 to I $4 \mathrm{~h}$ after irradiation was selected as the time for making counts of kappas in three separate experiments. Brights showed a marked increase in number after irradiation and non-brights a marked decrease (Table 1). These changes are statistically significant. It is assumed that the counts approximate Poisson distributions. However, the variances were found to be somewhat greater than expected. Therefore a square-root transformation was used, and a $t$-test on the paired differences between irradiated and control for the brights was calculated. We found $t$ to be 38 with 2 degrees of freedom and a probability of less than $0.00 \mathrm{I}$. A corresponding $t$ for the non-brights was 6.8 with the probability between 0.02 and 0.05 . A similar calculation showed that the decrease in total number of kappas (brights plus non-brights) in the irradiated group was not statistically significant.

\section{Effect of irradiation on killing activity of paramecia}

No consistent difference was observed between the strength of killing of control and irradiated animals homogenized at intervals between 4 and $24 \mathrm{~h}$ after irradiation. 


\section{DISCUSSION}

The present results were anticipated by Sonneborne (1959) when he first suggested that viruses might be concerned with killing by kappa. We have shown in these studies that u.v. induces $\mathrm{R}$ bodies, and presumably the helical phage-like elements. Direct counts of the helical phage-like structures are not feasible, for the structures are fragile and tend to fall off the $\mathrm{R}$ body during the preparation of the material for electron microscopy. Initially, as the non-brights are converted into brights it is found that the increase in brights is approximately equalled by the decrease in non-brights, the total number of kappas remaining constant. However, as the non-brights are lost, the total number of kappas declines until all or almost all are lost. The fact that the u.v. induction is observed as predicted constitutes strong evidence in favour of the view that the helical phage-like structures are viral in nature.

The work on induction reported here was carried out with u.v. on stock 5 I. Preliminary studies with other inducing agents (mitomycin $\mathrm{C}$, bromodeoxyuridine) and other stocks ( 7, I038) have not been successful. However, it has also become apparent that a careful adjustment of dosage, time of exposure and other conditions are very important in detecting the effect. Whether a bacterium is inducible or not depends upon the genetic constitution of the phage, and it may well be that many of the phage-like elements in the different stocks of killers are not inducible with u.v. or other inducing agents.

The toxin which kills sensitive paramecia is associated with the bright kappas and a role for the $\mathrm{R}$ body in delivering the toxin to its site of action within sensitive paramecia now seems likely (Jurand et al. 197I). Therefore, it was expected that an increase in killing activity should have accompanied the roughly twofold increase in number of $\mathrm{R}$ bodies (see Table I). No such increase, however, was observed. It may be that u.v. damages the capacity of the brights to kill or that brights must undergo a period of maturation after formation before they become effective in killing as suggested by Sonneborn (I959). In any case, the reason for the discrepancy is not known.

Finally, it should be pointed out that the phage-like structures in stock 5I studied here are helical in form, and morphologically not quite so typical of phages as the spherical structures with hexagonal outlines found in the other stocks of killers such as 7 and 562 . No evidence of infection has thus far been found for any of the phage-like elements. It may be that all are defective phages or elements more closely related to other classes of bacterial extrachromosomal determinants such as bacteriocin factors, rather than typical bacteriophages.

This paper is contribution 916 from the Zoology Department, Indiana University, Bloomington, Indiana, U.S.A. Work was supported by grant GB-27609 from the National Science Foundation.

\section{REFERENCES}

Beale, G. H., Jurand, A. \& Preer, J. R., Jun. (1969). The classes of endosymbiont of Paramecium aurelia. Journal of Cell Science 5, 65-9I.

Grimes, G. W. \& PreER, J. R., JUN. (I97I). Further observations on the correlation between kappa and phage-like particles in paramecium. Genetical Research 18, I 15-1 16.

Heatherington, S. (1934). The sterilization of protozoa. Biological Bulletin 67, 31 5-32 I.

Jurand, A., Rudman, B. M. \& Preer, J. R., Jun. (1971). Prelethal effects of killing action by stock 7 of Paramecium aurelia. Journal of Experimental Zoology I77, 365-387.

Mueller, J. A. (1963). Separation of kappa particles with infective activity from those with killing activity and identification of the infective particles in Paramecium aurelia. Experimental Cell Research 30, 492508. 
Preer, J. R., JUn. (1950). Microscopically visible bodies in the cytoplasm of the 'killer' strains of $P$. aurelia. Genetics 35, 344-362.

Preer, J. R., Jun. (I97I). Extrachromosomal inheritance: hereditary symbionts, mitochondria, chloroplasts. Annual Review of Genetics 5, 36I-406.

Preer, J. R., Jun. \& Jurand, A. (I968). The relation between virus-like particles and R bodies of Paramecium aurelia. Genetical Research 12, 33I-340.

Preer, J. R., Jun. \& Preer, L. B. (1967). Virus-like bodies in killer paramecia. Proceedings of the National Academy of Sciences of the United States of America 58, I774-1781.

Preer, J. R., Jun., Preer, L. B. \& Jurand, A. (1973). Kappa and other endosymbionts in Paramecium aurelia. Bacteriological Reviews (in the Press).

Preer, J. R., Jun., Preer, L. B., Rudman, B. \& Jurand, A. (I971). Isolation and composition of bacteriophage-like particles from kappa of killer paramecia. Molecular and General Genetics IIr, 202-208.

Preer, J. R., Jun., Siegel, R. W. \& Stark, P. S. (1953). The relationship between kappa and paramecia in Paramecium aurelia. Proceedings of the National Academy of Sciences of the United States of America 39 , 1228-1 233.

Preer, J. R., Jun. \& Stark, P. (I953). Cytological observations on the cytoplasmic factor 'kappa' in Paramecium aurelia. Experimental Cell Research 5, 478-49I.

Preer, L. B., Jurand, A., Preer, J. R., Jun. \& Rudman, B. M. (1972). The classes of kappa in Paramecium aurelia. Journal of Cell Science $\mathrm{xI}, 58 \mathrm{I}-600$.

Sonneborn, T. M. (1943). Gene and cytoplasm. I. The determination and inheritance of the killer character in variety 4 of $P$. aurelia. II. The bearing of determination and inheritance of characters in $P$. aurelia on problems of cytoplasmic inheritance, pneumococcus transformations, mutations and development. Proceedings of the National Academy of Sciences of the United States of America 29, 329-343.

Sonneborn, T. M. (1959). Kappa and related particles in paramecium. In Advances in Virus Research, pp. 229-356. New York: Academic Press.

Sonneborn, T. M. (1970). Methods in paramecium research. In Methods in Cell Physiology, vol. 4, pp. 24I339. New York: Academic Press.

Sмiтh, J. E. (1961). Purification of kappa particles of Paramecium aurelia, stock 51. American Zoologist $\mathbf{1}$, 390. 